\title{
Fabrication of Zinc Oxide and Nanostructured Porous Silicon Composite Micropatterns on Silicon
}

\author{
Rehab Ramadan ${ }^{1,2, *(\mathbb{D})}$, Vicente Torres-Costa ${ }^{1}$ and Raúl J. Martín-Palma ${ }^{1,3}$ \\ 1 Departamento de Física Aplicada, Universidad Autónoma de Madrid, 28049 Madrid, Spain; \\ vicente.torres@uam.es (V.T.-C.); rauljose.martin@uam.es (R.J.M.-P.) \\ 2 Department of Physics, Faculty of Science, Minia University, Minia 61519, Egypt \\ 3 Instituto de Ciencia de Materiales Nicolás Cabrera, Universidad Autónoma de Madrid, 28049 Madrid, Spain \\ * Correspondence: rehab.ramadan@uam.es; Tel.: +34-914974919
}

Received: 30 April 2020; Accepted: 28 May 2020; Published: 30 May 2020

\begin{abstract}
The luminescent properties of zinc oxide ( $\mathrm{ZnO})$ and nanostructured porous silicon (PSi) make these materials very appealing for photoemission applications. The current study reports on the fabrication of a composite of $\mathrm{ZnO}$ and nanostructured porous silicon micropatterns ( $\mathrm{ZnO}+\mathrm{PSi}$ micropatterns) onto heavily-doped silicon surfaces. The proposed composite micropattern is devoted to the future development of light-emitting diodes. The fabrication of the $\mathrm{ZnO}+\mathrm{PSi}$ micropatterns was carried out in a two-step process. (1) A regular hexagonal micropattern of a photoresist/ZnO stack was fabricated by UV lithography on crystalline silicon substrates. (2) Before being lifted off the photoresist, nanostructured PSi micropatterns were fabricated by electrochemically etching the exposed areas of the silicon substrate. Subsequently, wet etching of the photoresist was carried out for the final development of the composite $\mathrm{ZnO}$ and PSi micropatterns. Further, thin films of $\mathrm{ZnO}$ and nanostructured PSi layers were characterized. In particular, their photoluminescent properties were analyzed, as well as their morphology and composition. The experimental PL results show that the $\mathrm{ZnO}$ layers have emission broadbands centered at $(2.63 \mathrm{eV}$, blue), while the PSi layers show a band centered at $(1.71 \mathrm{eV}$, red). Further, the emission peaks from the PSi layers can be tuned by changing their fabrication conditions. It was observed that the properties of the $\mathrm{ZnO}$ thin films are not influenced by either the surface morphology of PSi or by its PL emissions. Therefore, the PL properties of the composite $\mathrm{ZnO}+\mathrm{PSi}$ micropatterns are equivalent to those featuring the addition of PSi layers and $\mathrm{ZnO}$ thin films. Accordingly, broadband optical emissions are expected to arise from a combination between the ZnO layer (blue band) and PSi (red band). Furthermore, the electrical losses associated with the PSi areas can be greatly reduced since $\mathrm{ZnO}$ is in contact with the Si surface. As a result, the proposed composite micropatterns might be attractive for many solid-state lighting applications, such as light-emitting diodes.
\end{abstract}

Keywords: energy gap; photoluminescence; $\mathrm{ZnO}$ and nanostructured porous silicon micropatterns

\section{Introduction}

The many useful physico-chemical properties of zinc oxide $(\mathrm{ZnO})$ can be exploited in various potential applications [1], for instance, in optoelectronic applications for the fabrication of efficient photo-detectors [2], light-emitting diodes [3], and photovoltaic devices [4], or even in the field of biomedical sensing [5]. ZnO is a well-known luminescent material [6]. Usually, its photoluminescence (PL) spectrum has UV band emissions centered at $3.3 \mathrm{eV}$, which represents the typical bandgap (Eg) of $\mathrm{ZnO}$ thin films [7,8]. However, in some cases, a blueshift in the position of the emission band or in the presence of another visible blue broadband occurs. In more detail, the reduction in the $E g$ of $\mathrm{ZnO}$ thin films depends on the size of the nanocrystals and their shape [9-11]. 
The red emission from porous silicon (PSi) layers was first observed by Canham [12]. The particular position of the emission band depends on the Si crystal size [13]. An increase in the effective Eg of the PSi layer is attributed to a decrease in the $\mathrm{Si}$ crystallite size [14]. ZnO has been widely investigated in different structural forms on porous silicon templates [15,16]. The growth of $\mathrm{ZnO}$ thin films on PSi surfaces results in a notable enhancement in the PL properties of the composite, as previously reported $[15,17,18]$. However, PSi has lower electrical conduction than $\mathrm{Si}$, which leads to limited conduction through optoelectronic devices $[19,20]$. Thus, the objective of the present work is to combine PSi and $\mathrm{ZnO}$ thin films to enhance PL emission properties and at the same time preserve electrical conduction.

In the present study, the morphology and bandgap of $\mathrm{ZnO}$ thin films and PSi layers were determined from the experimental PL spectra. Afterwards, regular hexagonal thin film structures of $\mathrm{ZnO}$ were grown on crystalline $\mathrm{Si}$ substrates. PSi nanostructures were subsequently fabricated in the $\mathrm{Si}$ areas between the hexagonal $\mathrm{ZnO}$ micropatterns, leading to $\mathrm{ZnO}$ and nanostructured PSi composite micropatterns. These structure are of interest in the development of optoelectronic devices for two main reasons. (1) The PL emissions can be enhanced by combining blue emissions from the $\mathrm{ZnO}$ micropattern with red emissions from the PSi nanostructures. (2) The electrical losses associated with the PSi areas can be greatly reduced since $\mathrm{ZnO}$ is in contact with the Si surface.

\section{Materials and Methods}

\subsection{ZnO Thin Film Deposition}

Electron beam evaporation was used to grow $\mathrm{ZnO}$ thin films on crystalline boron-doped silicon $<100>$ substrates, with resistivity of $0.8-2 \Omega \cdot \mathrm{cm}$. The area of the samples was $1.5 \mathrm{~cm} \times 1.5 \mathrm{~cm}$. The source material was $\mathrm{ZnO}(99.9 \%)$, which was purchased from the Kurt J. Lesker Company. The typical base pressure was $2 \times 10^{-7}$ Torr, which grew to 1 to $2 \times 10^{-5}$ Torr during the evaporation process that was carried out without introducing any reactive gases in the deposition chamber. The e-beam emission current was $20 \mathrm{~mA}$, and the deposition time was $30 \mathrm{~min}$. The films possessed a brownish color after evaporation. For this reason, to improve the optical transparency of the $\mathrm{ZnO}$ thin films, thermal annealing at $350{ }^{\circ} \mathrm{C}$ was carried out in an air atmosphere for $30 \mathrm{~min}$.

\subsection{Fabrication of $\mathrm{ZnO}$ Micropatterns by UV-Lithography}

The surface micropatterns of $\mathrm{ZnO}$ thin films were fabricated using a photolithographic technique with a negative photoresist (Ariston 20 series). The photoresist was deposited by spin casting, where the spin time was $30 \mathrm{~s}$, and the spin speed was $3000 \mathrm{rpm}$. Afterwards, the deposited photoresist was dried on a hot plate at $70^{\circ} \mathrm{C}$ for $15 \mathrm{~min}$. The photoresist/ZnO stack layers were then exposed for $3 \mathrm{~min}$ to UV radiation (Hamamatsu LC-L1 UV-led spotlight source, $1 \mathrm{~W} . \mathrm{cm}^{-2}$ ) through a hexagonally-structured photomask. Before the lift-off step of the photoresist micropattern, nanostructured porous silicon was fabricated on the exposed silicon areas among the photoresist/ZnO micropattern, as explained in the next subsection. Subsequently, the photoresist was developed by immersing the sample in $0.25 \mathrm{M}$ of $\mathrm{NaOH}$ for $1 \mathrm{~min}$, followed by wet etching of $\mathrm{ZnO}$ residuals in $\mathrm{HF} / \mathrm{H}_{2} \mathrm{O}(1: 20)$ solution for $10 \mathrm{~s}$.

\subsection{Fabrication of Spongy Nanostructured PSi}

Photoresist/ZnO-micropatterned stacks were used for electrochemical etching of the exposed silicon areas. The samples were mounted in a sample holder with an active area of $1.23 \mathrm{~cm}^{2}$ and then exposed to the etching solution. The etching solution consisted of a (1:4) mixture of HF (48\%)/ethanol $(99 \%)$. The applied current density was $8 \mathrm{~mA} / \mathrm{cm}^{2}$, and the etching time was $100 \mathrm{~s}$, leading to sponge-like nanostructures. The composite $\mathrm{ZnO}+\mathrm{PSi}$ micropatterns were developed after lifting the samples off the photoresist in acetone for $1 \mathrm{~min}$. Finally, the samples were cleaned using ethanol, followed by distilled water, and were finally dried with nitrogen steam. A schematic representation of the fabrication process is shown in Figure 1. 


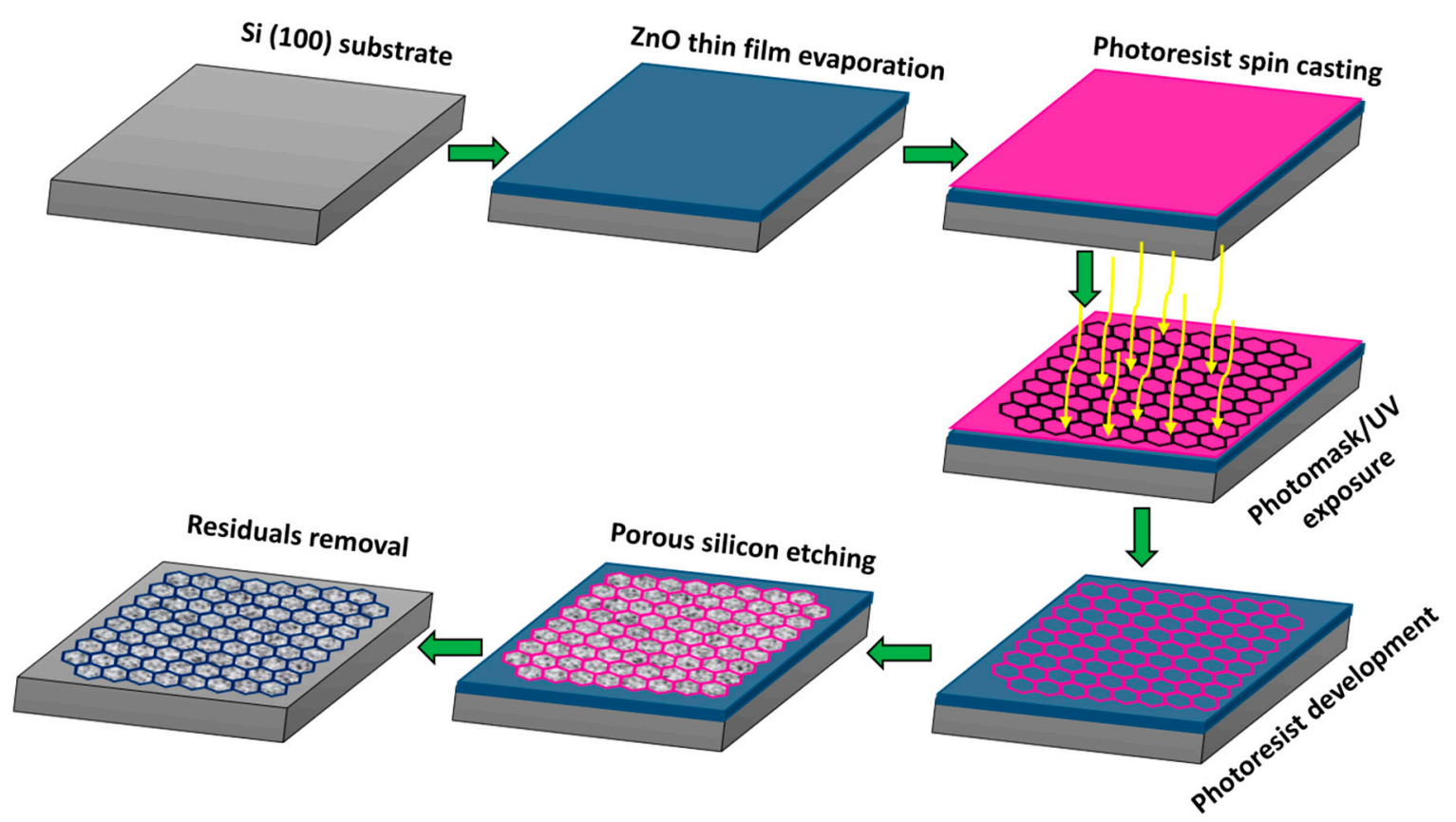

Figure 1. Schematic representation of the steps followed for the fabrication of the $\mathrm{ZnO}+\mathrm{PSi}$ composite micropatterns on silicon substrates.

\subsection{Characterization Techniques}

Photoluminescence measurements were carried out using a spectrofluorometer (SLM-Aminco Bowman AB2 series, Rochester, NY, USA) provided with a $150 \mathrm{~W}$ Xe lamp for excitation. Photoluminescence emissions were collected at a $90^{\circ}$ angle from the excitation beam.

The morphology of the thin films was studied by field emission scanning electron microscopy (FESEM, XL-40 FEG, Philips, Eindhoven, The Netherlands) operated at $10 \mathrm{kV}$. An energy dispersive spectroscopy X-ray analyzer (EDX, Inca X-sight 7558, Oxford Instruments, London, UK) coupled to the microscope was used to determine the elemental compositions of the films in addition to composition mapping.

\section{Results and Discussion}

\subsection{Photoluminescence Properties of PSi and $\mathrm{ZnO}$ Layers}

Photoluminescence (PL) is a very useful tool for the study of the electronic and optoelectronic properties of materials since PL spectra are intimately related to the band structure of semiconductors and nanostructures [21]. In this work, photoluminescence spectroscopy was used to study the light emission properties of PSi and $\mathrm{ZnO}$ layers to determine the bandgap of these materials. Figure 2 shows the PL spectra in the $400-750 \mathrm{~nm}$ wavelength range of the $\mathrm{ZnO}$ and PSi layers, which were taken using an excitation wavelength of $225 \mathrm{~nm}$ (UV excitation). Since both the PSi and $\mathrm{ZnO}$ layers were grown onto silicon substrates, the experimental PL data were normalized to the silicon spectrum.

Thin films of $\mathrm{ZnO}$ typically show an allowable bandgap transition in the 3 to $3.3 \mathrm{eV}(375-410 \mathrm{~nm})$ interval, depending on the film thickness and the specific treatment after deposition [22,23]. In the case of $\mathrm{ZnO}$ nanostructures, including $\mathrm{ZnO}$ nanowires, nanorods, and nanobelts [9-11,24], a blueshift in the emission band of the PL spectra was previously reported, as well as the presence of an additional higher broadband emission centered between 2 and $3 \mathrm{eV}[10,11]$. Overall, a decrease in the bandgap occurs, which depends on the size and shape of the nanostructure. 


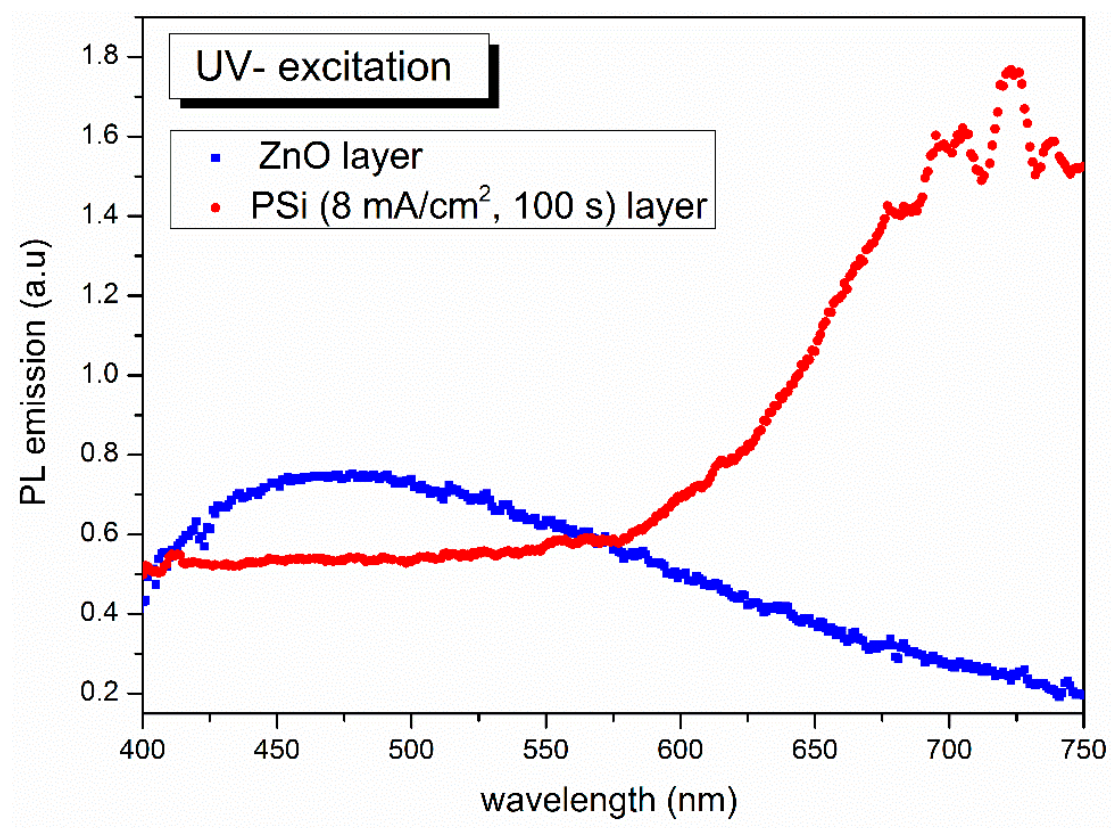

Figure 2. PL emission spectra from a typical $\mathrm{ZnO}$ thin film and a PSi layer under UV excitation at $255 \mathrm{~nm}$.

In the current study, a broad emission band centered at $470 \mathrm{~nm}(2.63 \mathrm{eV})$ was observed for the thin layers of $\mathrm{ZnO}$, which is the value of the bandgap. This band might be associated with the presence of oxygen vacancies in the $\mathrm{ZnO}$ layer, as already reported by many authors $[15,25,26]$. The broad shape of this band could be due to a number of factors, including inhomogeneous thin layer thickness, composition, nanocrystal size, and variation in the stoichiometry of the $\mathrm{ZnO}$ thin films. All or part of these effects might also be responsible for the reduction in the bandgap value to $2.63 \mathrm{eV}$. Another mechanism might be responsible for the narrowing of the bandgap of $\mathrm{ZnO}$. As previously reported [27], the visible emissions from micro- and nano-crystalline $\mathrm{ZnO}$ are attributed to a transition from photogenerated electrons in the conduction band to a deeply trapped hole in the valence band, which effectively reduces the band gap value of $\mathrm{ZnO}$ micro- and nano-structures. The characteristic morphology of the $\mathrm{ZnO}$ thin films is shown in the top-view FESEM image of Figure 3a, and a magnified cross- sectional image is shown in Figure $3 \mathrm{~b}$, which confirms the small size of the $\mathrm{ZnO}$ nanocrystals and the presence of some cavities in the layer due to this small thickness, where the typical crystal size is estimated to be around $30-40 \mathrm{~nm}$.

Additionally, the PSi layers show several emission peaks in the 690 to $740 \mathrm{~nm}$ wavelength range, with the main one centered at $725 \mathrm{~nm}$. The origin of light emissions from the PSi nanostructures is generally attributed to two types of luminescence mechanisms, namely the manifestation of quantum confinement effects and the presence of radiative defects in the thin films [28].

PSi is usually described as a material composed of Si nanocrystals embedded in an amorphous matrix [29,30]. A typical structure is shown in Figure 3c. Additionally, a magnified image is shown in Figure $3 \mathrm{~d}$. Using the Imagej software package, the pore diameter of the fabricated PSi nanostructures was calculated to be in the range of $20-50 \mathrm{~nm}$ for the spherical nano-holes and was larger, in the range of 75-200 nm, for the linear cracks. Accordingly, the PL emission in the visible is attributed to quantum confinement in the nanocrystals, which results in an increased bandgap value compared to that of bulk $\mathrm{Si}(1.12 \mathrm{eV})$ [31]. An increase in porosity results in a reduction of the size of the $\mathrm{Si}$ nanocrystals, which results in a band position blueshift, and vice versa [15]. In our case, the emission band was located in the red region of the visible spectrum and centered at $1.71 \mathrm{eV}$. This result is in a good agreement with previously reported studies on silicon quantum dots and porous silicon [13,28]. 

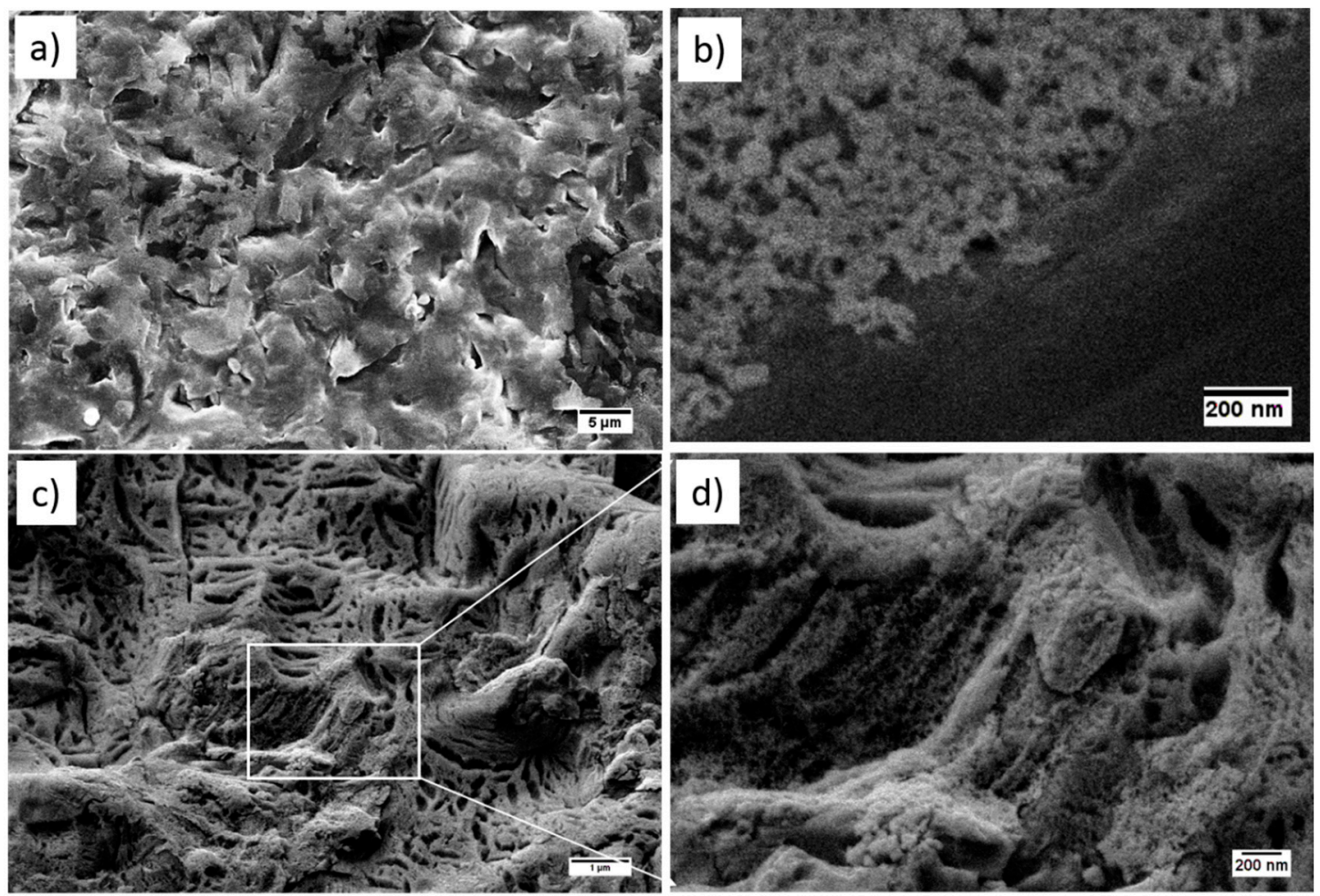

Figure 3. FESEM images: (a) a top-view of the $\mathrm{ZnO}$ layer, (b) a cross-sectional view under a higher magnification of a defined area in the $\mathrm{ZnO}$ film, (c) top-view of the PSi layer prepared at an $8 \mathrm{~mA} / \mathrm{cm}^{2}$ current density, and (d) a higher magnification top-view image of a defined area in the PSi layer.

\section{2. $\mathrm{ZnO}+$ PSi Surface Micropatterns}

To fabricate $\mathrm{ZnO}+\mathrm{PSi}$ micropatterns, regular hexagonal thin film structures of $\mathrm{ZnO}$ (line widths$190 \mu \mathrm{m}$ ) were grown on crystalline Si substrates. Spongy PSi nanostructures (shown in Figure 3c) were subsequently fabricated by electrochemically etching the exposed $\mathrm{Si}$ areas between the $\mathrm{ZnO}$ micropatterns. FESEM combined with EDX were used to determine the elemental composition map of the $\mathrm{ZnO}+\mathrm{PSi}$ surface micropatterns. The results are presented in Figure 4. An interwoven image of all the elemental composition of the system is shown in Figure $4 \mathrm{~b}$. In detail, Figure $4 \mathrm{c}-\mathrm{e}$ displays the $\mathrm{Zn}$, $\mathrm{O}$, and Si surface distributions. Map $4 \mathrm{~d}$ shows that the largest percentage of $\mathrm{O}$ atoms is located in the $\mathrm{ZnO}$ film areas due to the oxygen vacancies in the $\mathrm{ZnO}$ layer, as discussed in Section 3.1. These results show that the $\mathrm{ZnO}$ and PSi areas are well defined with minimal mixing. This will help avoid any influence of one material on another for photoluminescence, as is the case for $\mathrm{ZnO}$-infiltrated PSi films [32].

Figure 5 shows a semiquantitative EDX analysis of the $\mathrm{ZnO}+\mathrm{PSi}$ micropatterns. In particular, Figure 5 a shows the elemental composition in a spot taken from the PSi area, and Figure $5 b$ focuses on an area in the $\mathrm{ZnO}$ micropattern. The practical results confirm that, as expected, $\mathrm{Si}$ and $\mathrm{O}$ are the main elements composing the PSi layer, whereas $\mathrm{Si}, \mathrm{O}$, and $\mathrm{Zn}$ are the main elements of the $\mathrm{ZnO}$ micropattern layer. In the latter case, the Si signal comes from the underlying Si substrate. This fact confirms the small thickness of the $\mathrm{ZnO}$ layers. Furthermore, the films show good compositional homogeneity and are free from contamination. 


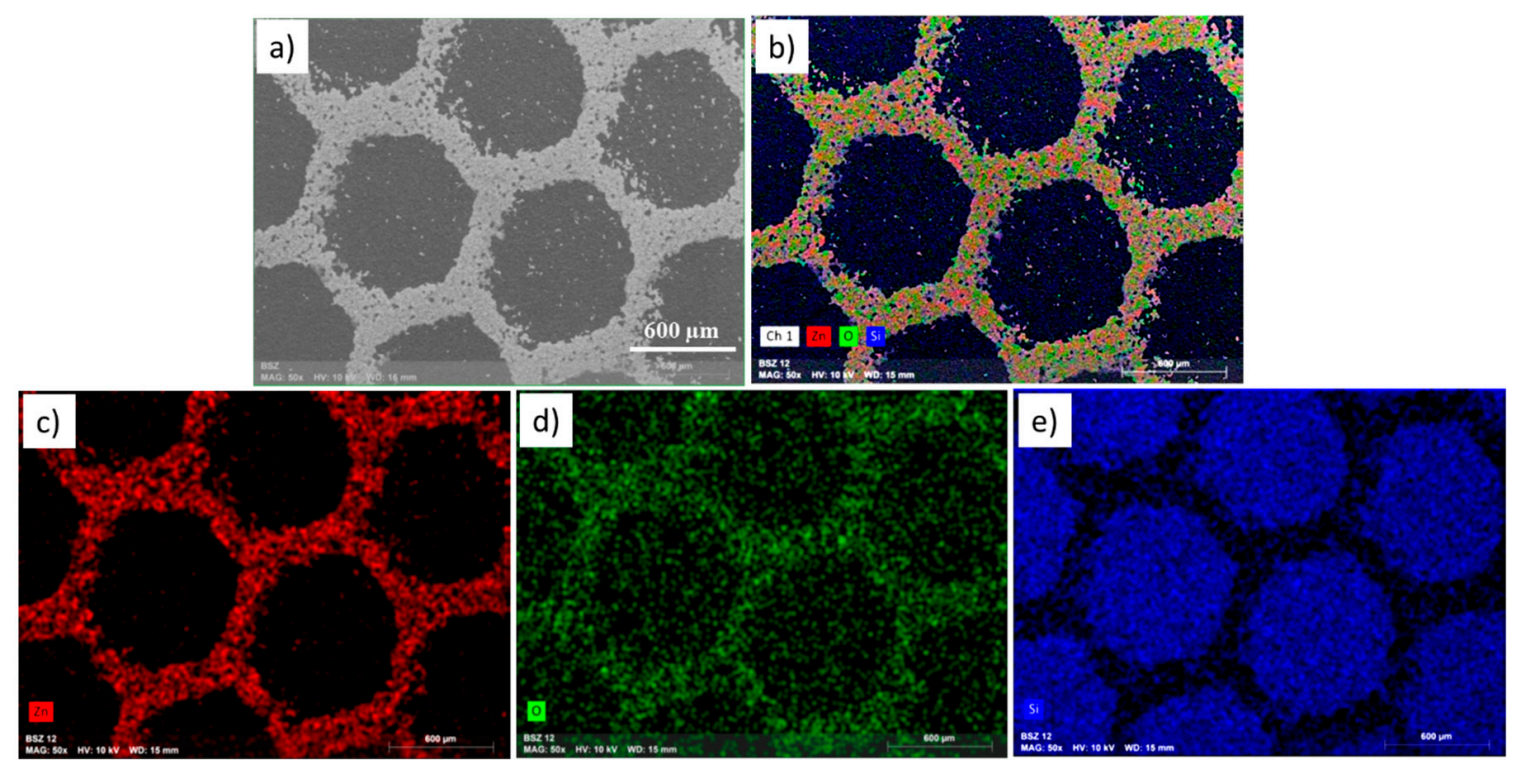

Figure 4. (a) FESEM image of the nanostructured $\mathrm{ZnO}+$ PSi micropatterns, (b) EDX complementary map of $\mathrm{Zn}, \mathrm{O}$, and $\mathrm{Si}$ distribution in the $\mathrm{ZnO}+$ PSi layer; $(\mathbf{c}-\mathbf{e})$ indicate the EDX maps for $\mathrm{Zn}, \mathrm{O}$, and $\mathrm{Si}$, respectively.

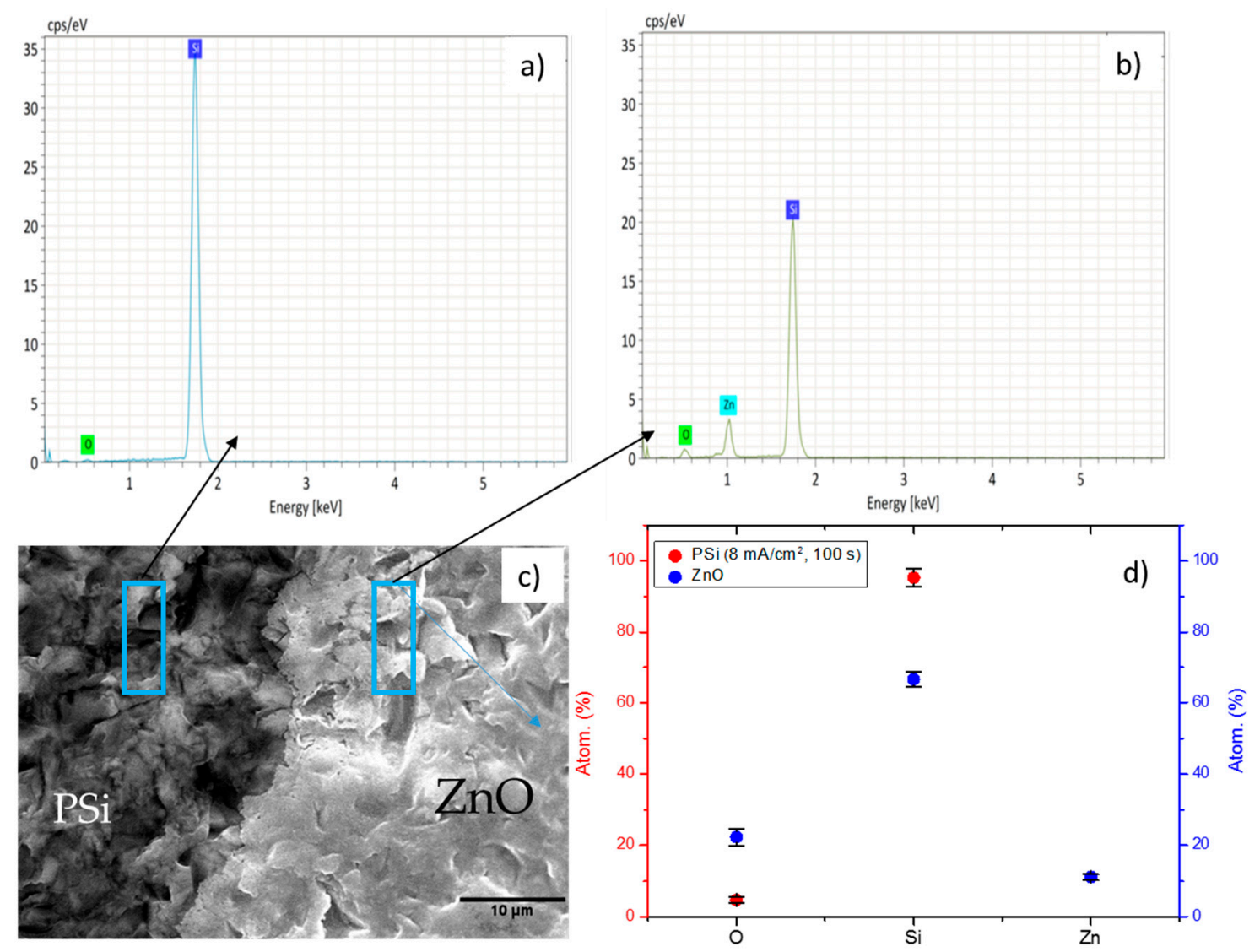

Figure 5. EDX microanalysis of the elemental composition of the $\mathrm{ZnO}+\mathrm{PSi}$ micropattern sample: (a) EDX analysis of the PSi layer, (b) EDX analysis of the ZnO micropattern layer, (c) FESEM top-view image of the two structures, and (d) a chart comparing the variations of the atomic percentage of the main elements in the PSi and $\mathrm{ZnO}$ micropattern layers.

Figure 5c shows a typical FESEM image of the two regions of the sample under study, highlighting the different morphologies of PSi and $\mathrm{ZnO}$. The atomic percentages of $\mathrm{Si}, \mathrm{O}$, and $\mathrm{Zn}$ in the two regions 
of the $\mathrm{ZnO}+\mathrm{PSi}$ micropatterns are presented in Figure 5d. Since PSi can be described simply as an amorphous homogeneous matrix of Si nanocrystals and air, its main elements are Si and O [31]. Furthermore, the atomic percentage variations shown in Figure $5 \mathrm{~d}$ are consistent with the surface composition maps in Figure 4c-e.

\section{Conclusions}

The luminescent properties and morphology of $\mathrm{ZnO}$ thin films and nanostructured porous silicon (PSi) layers were analyzed by a combination of photoluminescence (PL) spectroscopy, scanning electron microscopy (SEM), and energy dispersive X-ray (EDX) analysis. The experimental PL spectra show blue broadband emissions for $\mathrm{ZnO}$ thin films centered at $2.63 \mathrm{eV}$ and a red band centered at $1.71 \mathrm{eV}$ for PSi layers. The origin for the blue light emissions from $\mathrm{ZnO}$ thin films is associated with the presence of oxygen vacancies in these films. Moreover, the broad shape of the band, as well as the shift in the bandgap value, might be related to several factors, including inhomogeneous thin layer thickness, composition, nanocrystal size and shape, and variation in the stoichiometry of the layers. The manifestation of quantum confinement effects and the presence of radiative defects in the PSi layers are, in general, the reason for the red emissions from those layers. Moreover, the emission peaks from the PSi layers can be tuned by changing their fabrication conditions.

Furthermore, hexagonal $\mathrm{ZnO}+\mathrm{PSi}$ micropatterns were fabricated on heavily-doped crystalline silicon substrates. These structures are expected to reduce the electrical losses associated with the PSi areas since $\mathrm{ZnO}$ is in contact with the higly-doped Si surface. Additionally they enhance the PL emissions by combining blue emissions from the $\mathrm{ZnO}$ areas with red emissions from the PSi nanostructures.

Ultimately, the composite $\mathrm{ZnO}+\mathrm{PSi}$ micropatterns could be of interest for photoemission applications. Since the $\mathrm{ZnO}$ micropatterns are not in contact with the PSi areas, the properties of $\mathrm{ZnO}$ will not be affected by the underlying surface structure of PSi nor by the sizes of the nanocrystals. At the same time, the PL emissions from the PSi layers will be unaffected by the properties of the $\mathrm{ZnO}$ thin films. As such, the PL emissions of the composite $\mathrm{ZnO}+\mathrm{PSi}$ micropatterns are equivalent to the addition of the emissions from PSi and ZnO. Accordingly, emissions in the visible spectrum feature a combination of the blue and red bands. This is in stark contrast to the case where $\mathrm{ZnO}$ is embedded inside the PSi structure; in this case, the luminescence of each material is affected by the presence of the other, and the overall PL of the structure strongly depends on the fabrication and post treatments [32]. As a result, the proposed composite is attractive for many solid-state lighting applications, such as light-emitting diodes.

Author Contributions: Methodology, R.R.; validation, R.R.; formal analysis, R.R., V.T.-C., and R.J.M.-P.; investigation, R.R. and V.T.-C.; data curation, R.R., V.T.-C., and R.J.M.-P.; supervision, R.J.M.-P.; project administration, R.J.M.-P.; funding acquisition, R.J.M.-P. All authors have read and agreed to the published version of the manuscript.

Funding: This research was partially funded by Universidad Autónoma de Madrid, FPI-UAM grant (2019) and by the Egyptian Ministry of Higher Education, Missions Section under Egyptian Joint Supervision Grant, call 015/016.

Acknowledgments: The authors are thankful to Luis García Pelayo and Valentin Constantin Nistor for their technical support.

Conflicts of Interest: The authors declare no conflict of interest.

\section{References}

1. Wang, Z.L. Zinc oxide nanostructures: Growth, properties and applications. J. Phys. Condens Matter 2004, 16, R829. [CrossRef]

2. Zhang, H.; Zhang, J.; Su, G.; Zhou, T.; Zhang, A. Ultraviolet photodetector on flexible polymer substrate based on nano zinc oxide and laser-induced selective metallization. Compos. Sci. Technol. 2020, 190, 108045. [CrossRef]

3. Rahman, F. Zinc oxide light-emitting diodes: A review. Opt. Eng. 2019, 58, 010901. [CrossRef] 
4. Frantz, J.A.; Myers, J.D.; Bekele, R.Y.; Sanghera, J.S. Microstructured ZnO Coatings for Improved Performance in Cu (In, Ga)Se2 Photovoltaic Devices. U.S. Patent Application No. 16/512,450, 7 November 2019.

5. Ramadan, R.; Romera, D.; Carrascón, R.D.; Cantero, M.; Aguilera-Correa, J.-J.; García Ruiz, J.P.; Esteban, J.; Silván, M.M. Sol-gel-deposited Ti-doped ZnO: Toward cell fouling transparent conductive oxides. ACS Omega 2019, 4, 11354-11363. [CrossRef] [PubMed]

6. Willander, M.; Nur, O.; Sadaf, J.R.; Qadir, M.I.; Zaman, S.; Zainelabdin, A.; Bano, N.; Hussain, I. Luminescence from zinc oxide nanostructures and polymers and their hybrid devices. Material. 2010, 3, 2643-2667. [CrossRef]

7. Ondo-Ndong, R.; Ferblantier, G.; Al Kalfioui, M.; Boyer, A.; Foucaran, A. Properties of RF magnetron sputtered zinc oxide thin films. J. Cryst. Growth 2003, 255, 130-135. [CrossRef]

8. Ramadan, R.; Simiz, J.G.; Ynsa, M.D.; Silván, M.M. Microwave plasma annealing of sol-gel deposited tantalum oxide and zinc oxide films. Vacuum 2018, 149, 336-342. [CrossRef]

9. Wei, Y.-F.; Chung, W.-Y.; Yang, C.-F.; Shen, J.-R.; Chen, C.-C. Using different ions in the hydrothermal method to enhance the photoluminescence properties of synthesized ZnO-based nanowires. Electronics 2019, 8, 446. [CrossRef]

10. Hu, H.; Huang, X.; Deng, C.; Chen, X.; Qian, Y. Hydrothermal synthesis of ZnO nanowires and nanobelts on a large scale. Mater. Chem. Phys. 2007, 106, 58-62. [CrossRef]

11. Klini, A.; Mourka, A.; Dinca, V.; Fotakis, C.; Claeyssens, F. ZnO nanorod micropatterning via laser-induced forward transfer. Appl. Phys. A 2007, 87, 17-22. [CrossRef]

12. Cullis, A.; Canham, L. Visible light emission due to quantum size effects in highly porous crystalline silicon. Nature 1991, 353, 335-338. [CrossRef]

13. Elhouichet, H.; Oueslati, M. Photoluminescence properties of porous silicon nanocomposites. Mater. Sci. Eng. B 2001, 79, 27-30. [CrossRef]

14. Mortezaali, A.; Sani, S.R.; Jooni, F.J. Correlation between porosity of porous silicon and optoelectronic properties. J. Non-Oxide Glasses 2009, 1, 293-299.

15. Liu, Y.; Liu, Y.; Yang, H.; Wang, W.; Ma, J.; Zhang, J.; Lu, Y.; Shen, D.; Fan, X. The optical properties of ZnO films grown on porous Si templates. J. Phys. D Appl. Phys. 2003, 36, 2705. [CrossRef]

16. Gallach-Pérez, D.; Muñoz-Noval, A.; García-Pelayo, L.; Manso-Silván, M.; Torres-Costa, V. Tunnel conduction regimes, white-light emission and band diagram of porous silicon-zinc oxide nanocomposites. J. Lumin. 2017, 191, 107-111. [CrossRef]

17. Singh, R.; Singh, F.; Agarwal, V.; Mehra, R. Photoluminescence studies of ZnO/porous silicon nanocomposites. J. Phys. D Appl. Phys. 2007, 40, 3090. [CrossRef]

18. Kumar, Y.; Herrera, M.; Singh, F.; Olive-Méndez, S.; Kanjilal, D.; Kumar, S.; Agarwal, V. Cathodoluminescence and photoluminescence of swift ion irradiation modified zinc oxide-porous silicon nanocomposite. Mater. Sci. Eng. B 2012, 177, 1476-1481. [CrossRef]

19. Ramadan, R.; Martín-Palma, R.J. Electrical characterization of MIS Schottky barrier diodes based on nanostructured porous silicon and silver nanoparticles with applications in solar cells. Energies 2020, 13, 2165. [CrossRef]

20. Zimin, S. Classification of electrical properties of porous silicon. Semiconductors 2000, 34, 353-357. [CrossRef]

21. Doi, T.; Marinescu, I.D.; Kurokawa, S. Advances in CMP Polishing Technologies; William Andrew: Norwich, NY, USA, 2011.

22. Wasan, R.S.; Nada, M.S.; Wesam, A.T.; Mohammed, A. Synthesis sol-gel derived highly transparent ZnO thin films for optoelectronic applications. Adv. Mater. Phys. Chem. 2012, 2012, 17981.

23. Sharma, S.; Periasamy, C.; Chakrabarti, P. Thickness dependent study of RF sputtered ZnO thin films for optoelectronic device applications. Electron. Mater. Lett. 2015, 11, 1093-1101. [CrossRef]

24. Ou, Y.; Zhu, L.-W.; Xiao, W.-D.; Yang, H.-C.; Jiang, Q.-J.; Li, X.; Lu, J.-G.; Wan, L.-S.; Xu, Z.-K. Nonlithographic fabrication of nanostructured micropatterns via breath figures and solution growth. J. Phys. Chem. C 2014, 118, 4403-4409. [CrossRef]

25. Kumar, Y.; Herrera-Zaldivar, M.; Olive-Méndez, S.F.; Singh, F.; Mathew, X.; Agarwal, V. Modification of optical and electrical properties of zinc oxide-coated porous silicon nanostructures induced by swift heavy ion. Nanoscale Res. Lett. 2012, 7, 366. [CrossRef] [PubMed]

26. Juwhari, H.K.; Ikhmayies, S.J.; Lahlouh, B. Room temperature photoluminescence of spray-deposited ZnO thin films on glass substrates. Int. J. Hydrogen Energy 2017, 42, 17741-17747. [CrossRef] 
27. Van Dijken, A.; Meulenkamp, E.A.; Vanmaekelbergh, D.; Meijerink, A. The kinetics of the radiative and nonradiative processes in nanocrystalline ZnO particles upon photoexcitation. J. Phys. Chem. B 2000, 104, 1715-1723. [CrossRef]

28. Rezgui, B.; Sibai, A.; Nychyporuk, T.; Lemiti, M.; Brémond, G. Photoluminescence and optical absorption properties of silicon quantum dots embedded in Si-rich silicon nitride matrices. J. Lumin. 2009, 129, 1744-1746. [CrossRef]

29. Martın-Palma, R.; Pascual, L.; Herrero, P.; Martınez-Duart, J. Direct determination of grain sizes, lattice parameters, and mismatch of porous silicon. Appl. Phys. Lett. 2002, 81, 25-27. [CrossRef]

30. Martín-Palma, R.; Pascual, L.; Herrero, P.; Martínez-Duart, J. Monte Carlo determination of crystallite size of porous silicon from x-ray line broadening. Appl. Phys. Lett. 2005, 87, 211906. [CrossRef]

31. Ramadan, R.; Manso-Silván, M.; Martín-Palma, R.J. Hybrid porous silicon/silver nanostructures for the development of enhanced photovoltaic devices. J. Mater. Sci. 2020, 55, 5458-5470. [CrossRef]

32. Gallach, D.; Muñoz-Noval, A.; Torres-Costa, V.; Manso-Silván, M. Luminescence and fine structure correlation in $\mathrm{ZnO}$ permeated porous silicon nanocomposites. Phys. Chem. Chem. Phys. 2015, 17, 20597-20604. [CrossRef]

(C) 2020 by the authors. Licensee MDPI, Basel, Switzerland. This article is an open access article distributed under the terms and conditions of the Creative Commons Attribution (CC BY) license (http://creativecommons.org/licenses/by/4.0/). 